\title{
Efeito do retorno de lodo aeróbio sobre as características da biomassa presente em reatores UASB tratando esgoto sanitário
}

\author{
Effect of aerobic sludge return on the characteristics of anaerobic \\ biomass present in UASB reactors treating domestic sewage
}

\begin{abstract}
Patrícia Procópio Pontes
Engenheira Química. Doutora em Saneamento, Meio Ambiente e Recursos Hídricos pela Universidade Federal de Minas Gerais (UFMG). Professora do Departamento de Química do Centro Federal de Educação Tecnológica de Minas Gerais (Cefet-MG)
\end{abstract}

\section{Carlos Augusto de Lemos Chernicharo}

Engenheiro Civil e Sanitarista. Doutor em Engenharia Ambiental pela Universidade de Newcastle, Tyne, Reino Unido. Professor-associado do Departamento de Engenharia Sanitária e Ambiental da UFMG

\begin{abstract}
Resumo
O presente trabalho buscou avaliar a influência do retorno do lodo produzido em filtros biológicos percoladores (FBP) sobre as características da biomassa em reatores UASB utilizados para o tratamento de esgoto sanitário. Os experimentos foram conduzidos em reatores em escala piloto e em escala de demonstração, sendo que os reatores UASB foram operados com e sem retorno do lodo produzido nos FBP. Os resultados obtidos indicaram uma diminuição no diâmetro das partículas de lodo, durante as fases com retorno de lodo, mas apenas para as amostras de lodo tomadas nos pontos mais altos dos reatores anaeróbios. A estabilidade e a atividade metanogênica específica do lodo anaeróbio praticamente não se modificaram com o retorno de lodo. Conforme esperado, a produção específica de lodo anaeróbio aumentou com o retorno de lodo.
\end{abstract}

Palavras-chave: reator UASB; lodo anaeróbio; polímeros extracelulares; estabilidade do lodo; distribuição granulométrica.

\begin{abstract}
This work aimed at evaluating the influence of the return of excess aerobic sludge produced in trickling filters (TF) upon the biomass characteristics in UASB reactors used for the treatment of domestic sewage. The experiments were carried out in pilot and demonstration-scale reactors, with the UASB reactors being operated with and without the return of sludge produced in the TF. Smaller sludge particle sizes were observed when the aerobic sludge was returned to the UASB reactor, but only for sludge samples collected in the upper parts of the anaerobic reactors. Sludge stability and specific methanogenic activity were not affected by the return of sludge. As expected, the specific anaerobic sludge production increased with the return of sludge.
\end{abstract}

Keywords: UASB reactor; anaerobic sludge; extracellular polymers; sludge stability; granules size distribution.

\section{Introdução}

A combinação do processo de tratamento anaeróbio de águas residuárias com a digestão do lodo de descarte de unidades aeróbias utilizadas para o pós-tratamento do efluente anaeróbio por meio da combinação de reatores UASB e de filtros biológicos percoladores (FBP), por exemplo, pode conferir grande viabilidade econômica ao sistema de tratamento. Entretanto, apesar do avanço nos conhecimentos sobre o tratamento combinado de esgotos domésticos e lodo de descarte aeróbio em reatores UASB, pouco se sabe sobre a influência do retorno de lodo aeróbio nas características da biomassa no reator anaeróbio, tais como atividade metanogênica específica, estabilidade do lodo, sedimentabilidade ou tamanho dos grânulos. Essas características podem afetar a eficiência do tratamento anaeróbio ocasionando, eventualmente, um aumento ou diminuição da eficiência de remoção de matéria orgânica ou da sedimentabilidade do lodo.

O bom desempenho dos reatores UASB depende da manutenção, dentro dos reatores, de uma biomassa adaptada, com elevada atividade microbiana e resistente a choques, podendo ser favorecido pelo desenvolvimento de um agregado microbiano denso (grânulo).

Endereço para correspondência: Patrícia Procópio Pontes - Departamento de Química do Centro Federal de Educação Tecnológica de Minas Gerais Avenida Amazonas, 5.253, sala 401 - Nova Suíça - 30410-110 - Belo Horizonte (MG), Brasil - Tel.: (31) 3319-7151 - E-mail: patriciaprocopio@yahoo.com.br Recebido: 17/01/08 - Aceito: 23/10/08 - Reg. ABES: 010/08 
O tamanho dos grânulos é importante para a transferência metabólica, reduzindo a inibição dos micro-organismos (EL-MAMOUNI; LEDUC; GUIOT, 1998, LAGUNA et al, 1999). Boas características de sedimentação são obtidas pela formação de grânulos densos (CHERNICHARO, 1997), que podem atingir até $5 \mathrm{~mm}$ de diâmetro. A análise da distribuição granulométrica do lodo é um parâmetro importante para a sua caracterização (EL-MAMOUNI; LEDUC; GUIOT, 1998) e para o estudo de fatores físico-químicos causadores da granulação (LAGUNA et al, 1999).

O teor de polímeros extracelulares é outro parâmetro importante de caracterização do lodo, pois pode influenciar o tamanho dos grânulos e sua sedimentabilidade (CUERVO LOPEZ et al, 1999). O aumento na concentração de polímeros extracelulares é usualmente associado a piores condições de sedimentação do lodo. A adsorção de gordura na superfície do lodo pode limitar o transporte de substratos solúveis e diminuir a taxa de conversão de substratos (VIDAL, 2000). De acordo com Cuervo Lopez (1999), a relação proteínas/ carboidratos $(\mathrm{P} / \mathrm{C})$ poderia ser um melhor indicador da estabilidade do processo anaeróbio que o Índice Volumétrico do Lodo, pois se observou um aumento nessa relação nas pesquisas feitas pelo autor durante a flotação do lodo sem que alterações fossem observadas com o Índice Volumétrico do Lodo.

Tabela 1 - Características do sistema UASB/FBP em escala piloto

\begin{tabular}{lccc|} 
Característica & $\begin{array}{c}\text { Reator } \\
\text { UASB }\end{array}$ & $\begin{array}{c}\text { Compartimento } \\
\text { de reação }\end{array}$ & $\begin{array}{c}\text { Compartimento } \\
\text { de decantação }\end{array}$ \\
\hline Material & Acrílico & Polipropileno & Polipropileno \\
\hline Diâmetro $(\mathrm{m})$ & 0,30 & 0,30 & 0,30 \\
\hline Altura total $(\mathrm{m})$ & 4,20 & 2,00 & 1,50 \\
Volume útil $(\mathrm{L})$ & 420 & 135 & 106 \\
\hline Área superficial $\left(\mathrm{m}^{2}\right)$ & 0,071 & 0,071 & 0,071 \\
\hline
\end{tabular}

O presente trabalho buscou avaliar as características da biomassa de dois reatores UASB operando com e sem retorno de lodo aeróbio produzido em filtros biológicos percoladores. Apresentam-se os resultados obtidos para a composição do lodo em termos de polímeros extracelulares, distribuição granulométrica, estabilidade e atividade metanogênica específica. Dessa forma, pretende-se contribuir com a difusão de conhecimentos acerca de uma tecnologia de tratamento de esgotos bastante adequada às condições do país.

\section{Material e métodos}

\section{Aparato experimental}

Para avaliar o efeito do retorno de lodo aeróbio nas características da biomassa em reatores UASB, foram utilizados dois sistemas de tratamento de esgotos: um sistema reator UASB/FBP, em escala piloto, e um sistema compacto de tratamento de esgotos, em escala de demonstração, composto por um reator UASB na parte interna e um FBP na parte externa.

O sistema em escala piloto consistiu de um reator UASB, com volume de $420 \mathrm{~L}$, seguido de um FBP, utilizado para o pós-tratamento do efluente anaeróbio. O sistema reator UASB/FBP foi alimentado com esgoto doméstico retirado diretamente do interceptor da margem direita do ribeirão Arrudas, na cidade de Belo Horizonte, Minas Gerais. Os esgotos passavam pelas unidades de tratamento preliminar (cesto perfurado e caixa de areia) e por um tanque de acumulação/distribuição, todos localizados a montante do reator UASB. O sistema era automatizado e permitia a operação da planta em regime hidráulico transiente, de acordo com um hidrograma típico de vazões horárias. As características do sistema de tratamento em escala piloto são apresentadas na Tabela 1 e sua configuração, na Figura 1.

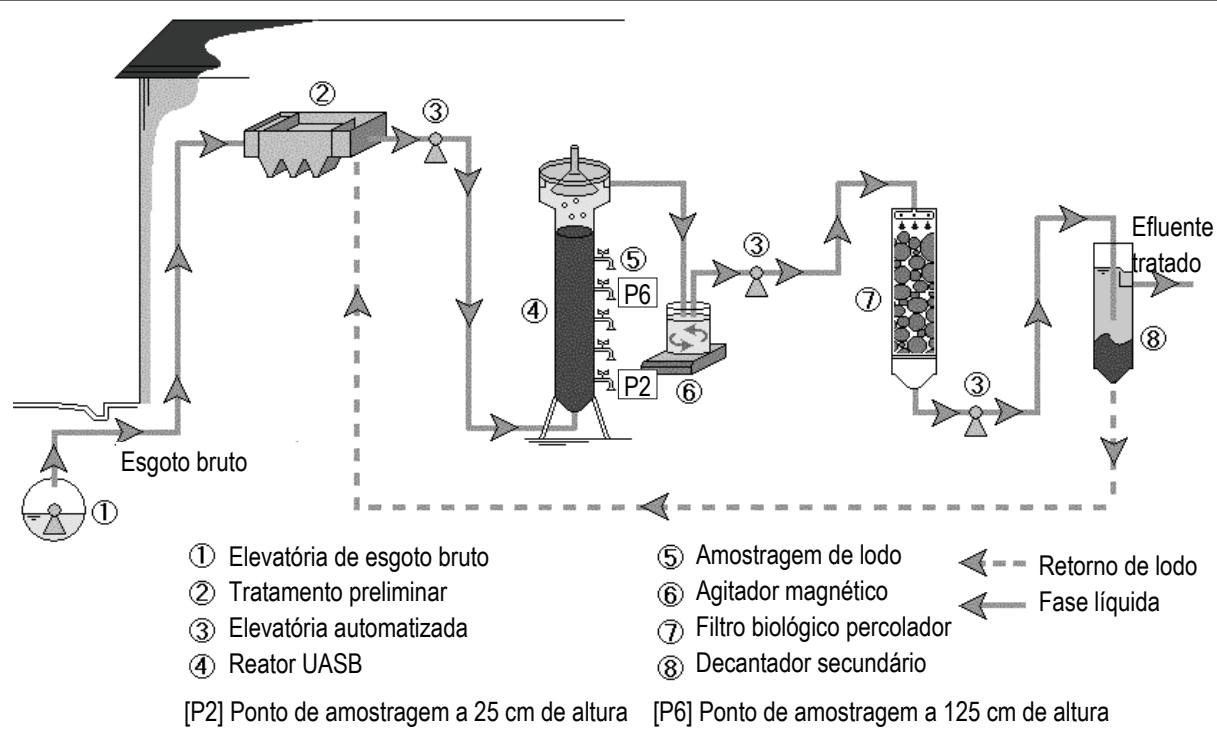

Figura 1 - Desenho esquemático do sistema UASB/FBP em escala piloto 


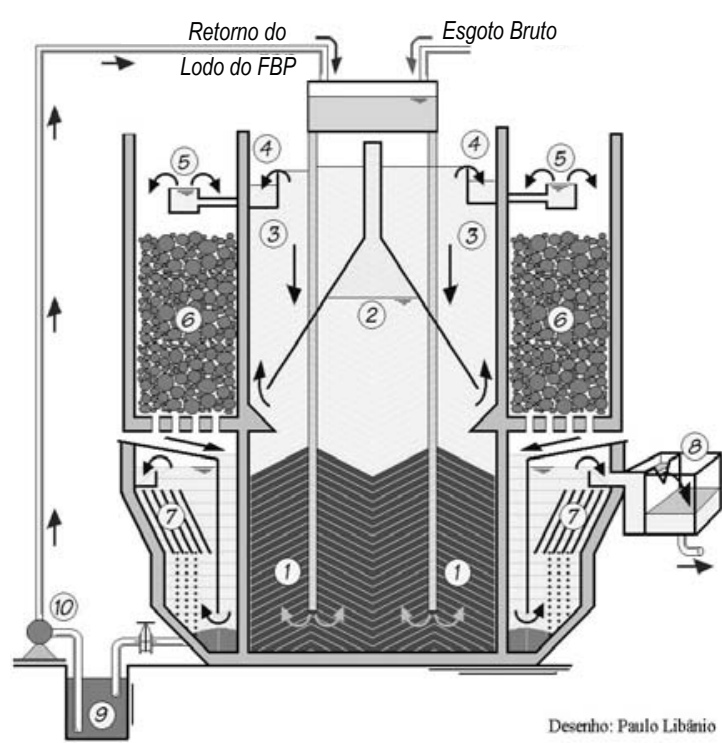

\section{Legenda}

(1) Tubo de distribuição do esgoto bruto

(2) Separador trifásico

(3) Compartimento de decantação

(4) Canaletas de coleta do efluente do reator UASB

(5) Canaletas de distribuição do efluente no FBP

(6) Meio suporte (escória de alto-forno)

(7) Decantadores lamelares

(8) Caixa de coleta do efluente do FBP

(9) Caixa de acumulação de lodo do FBP

(10) Bomba para retorno do lodo do FBP

Figura 2 - Corte esquemático do sistema UASB/FBP em escala de demonstração

Um corte esquemático do sistema compacto de tratamento de esgotos em escala de demonstração é apresentado na Figura 2, enquanto as suas principais características encontram-se na Tabela 2.

No sistema em escala de demonstração, o esgoto passava pelo tratamento preliminar e, em seguida, era introduzido no sistema compacto de tratamento pela parte inferior do reator UASB, seguindo um fluxo ascendente dentro deste. Um dispositivo trifásico de separação de sólidos, líquidos e gases se localizava na parte superior do reator e garantia a separação do gás contido na mistura líquida, propiciando a manutenção de condições ótimas de sedimentação no compartimento de decantação. Na região de decantação, o lodo mais pesado era removido da massa líquida retornando ao compartimento de digestão, enquanto as partículas mais leves eram perdidas do sistema junto com o efluente. O efluente, por sua vez, deixava o reator por meio de canaletas localizadas na parte superior do decantador, sendo distribuído, uniformemente, na parte superior do FBP, de onde apresentava uma trajetória descendente.

O FBP era dividido em dois compartimentos: um de reação, na parte superior, onde se encontra o meio suporte, e um inferior, de decantação, onde a biomassa e os sólidos que se desgarram do meio suporte ficavam retidos. O compartimento de reação consistia em um tanque preenchido com material de alta permeabilidade (escória de alto forno), sobre o qual os esgotos eram aplicados. O fundo do compartimento de reação era vazado, de maneira a permitir a passagem do líquido e possibilitar a ventilação do filtro, necessária para manter as condições aeróbias e o efetivo tratamento dos despejos pela via aeróbia. Após passar pelo meio suporte e ser drenado no fundo do FBP, o líquido era encaminhado a um decantador lamelar, localizado na parte inferior do filtro. Essa configuração de decantador
Tabela 2 - Características do sistema UASB/FBP em escala de demonstração

\begin{tabular}{lccc|} 
Característica & $\begin{array}{c}\text { Reator } \\
\text { UASB }\end{array}$ & $\begin{array}{c}\text { Filtro biológico percolador } \\
\text { Compartimento } \\
\text { de reação }\end{array}$ & $\begin{array}{c}\text { Compartimento } \\
\text { de decantação }\end{array}$ \\
\hline Material & Fibra de vidro & Fibra de vidro & Fibra de vidro \\
\hline Diâmetro externo $(\mathrm{m})$ & 2,51 & 4,1 & 4,1 \\
\hline Diâmetro interno $(\mathrm{m})$ & 2,5 & 2,51 & 2,51 \\
\hline Altura total $(\mathrm{m})$ & 4,5 & 1,9 & 1,75 \\
\hline Volume útil $\left(\mathrm{m}^{3}\right)$ & 22 & 11,5 & 7,25 \\
\hline Área superficial $\left(\mathrm{m}^{2}\right)$ & 4,9 & 7,6 & 7,6 \\
\hline
\end{tabular}

permitia que fossem aplicadas maiores taxas hidráulicas superficiais e, consequentemente, reduzia-se o tamanho do decantador. Os sólidos desgarrados do biofilme, ou não retidos no meio suporte pelos mecanismos de filtração e adsorção, sedimentavam no fundo do decantador, sendo removidos do efluente final, que era então coletado pela parte superior do decantador. O lodo sedimentado no fundo do decantador era descartado para um pequeno tanque de acumulação e bombeado de volta ao reator UASB, possibilitando a adoção de um sistema único de digestão do lodo aeróbio e anaeróbio, mais econômico e compacto

\section{Fases operacionais}

O trabalho foi desenvolvido em quatro fases operacionais, conforme apresentado na Tabela 3. As duas primeiras fases foram realizadas no sistema em escala piloto, enquanto a terceira e a quarta fase foram realizadas no sistema em escala de demonstração.

A primeira fase operacional foi realizada sem o retorno de lodo do FBP para o reator UASB e teve duração de 155 dias. Na segunda 
Tabela 3 - Características operacionais dos sistemas de tratamento

\begin{tabular}{|c|c|c|c|c|c|c|c|c|}
\hline \multirow{3}{*}{ Fase } & \multirow{3}{*}{ Sistema } & \multirow{3}{*}{$\begin{array}{c}\text { Retorno de lodo } \\
\text { aeróbio para o reator } \\
\text { UASB }\end{array}$} & \multicolumn{4}{|c|}{ Reator UASB } & \multicolumn{2}{|c|}{ FBP } \\
\hline & & & $\theta_{\mathrm{h}}$ & VA & Carga orgâni & a volumétrica & Altura MS & TAS \\
\hline & & & (h) & $\left(\mathrm{m} \cdot \mathrm{h}^{-1}\right)$ & $\left(\mathrm{kgDBO} \cdot \mathrm{m}^{-3} \cdot \mathrm{d}^{-1}\right)$ & $\left(\mathrm{kgDQO} \cdot \mathrm{m}^{-3} \cdot \mathrm{d}^{-1}\right)$ & (m) & $\left(m^{3} \cdot m^{-2} \cdot d^{-1}\right)$ \\
\hline 1 & Escala piloto & Não & 5,6 & 1,0 & 1,5 & 2,4 & 1,90 & 25,1 \\
\hline 2 & Escala piloto & Sim & 5,6 & 1,0 a 1,4 & 1,4 & 2,3 & 1,90 & 25,1 \\
\hline 3 & Escala demonstração & Não & 7,7 & 0,5 & 1,1 & 1,4 & 1,90 & 13,6 \\
\hline 4 & Escala demonstração & Sim & 7,7 & 0,5 a 0,6 & 0,9 & 1,4 & 1,90 & 13,6 \\
\hline
\end{tabular}

$\theta_{n}$ : tempo de detenção hidráulica médio; VA: velocidade ascensional média; TAS: taxa de aplicação superficial média; MS: meio suporte.

fase, com duração de 266 dias, foi implantada uma linha de recirculação de lodo, do FBP para o reator UASB, que consistia em um sistema de bombeamento semicontínuo, operado por quatro vezes a cada hora (com ciclos de operação de 20 segundos a cada 15 minutos) com uma vazão de 22,5 L.h ${ }^{-1}$. Apesar da vazão de lodo de retorno a cada ciclo de operação corresponder a 30\% da vazão média de entrada no reator UASB (74 L.h-1), a vazão média diária de lodo retorno para o reator UASB correspondia a apenas 12 L.d ${ }^{-1}$, equivalendo a $0,7 \%$ da vazão média de esgoto bruto introduzida no

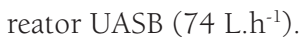

No sistema em escala de demonstração, utilizou-se uma vazão média afluente ao sistema igual a $2,88 \mathrm{~m}^{3} \cdot \mathrm{h}^{-1}$ (velocidade ascensional: $\left.0,5 \mathrm{~m} \cdot \mathrm{h}^{-1}\right)$. O sistema funcionou sem recirculação de lodo durante a fase 3 por um período de 58 dias e, durante a fase 4 , foi realizada a recirculação de lodo do FBP para o reator UASB por um período de 136 dias, a partir de uma pequena elevatória de retorno de lodo operada de forma intermitente ao longo do dia. Um sistema automatizado (liga/desliga) controlava o acionamento da bomba, de forma a possibilitar um ciclo de operação de 15 minutos, a cada hora com uma vazão de 2,22 L.min ${ }^{-1}$ a cada ciclo de operação. Tal vazão de recirculação era equivalente a $0,8 \%$ da vazão total afluente ao sistema.

\section{Monitoramento do sistema de tratamento}

Durante o monitoramento das unidades de tratamento, foram realizadas análises do esgoto bruto, do efluente do reator UASB e do efluente final do decantador secundário. Os parâmetros analisados foram: DBO (total e filtrada), DQO (total e filtrada), Sólidos Suspensos Totais, pH e temperatura. Para a maioria das coletas, foram realizadas amostragens compostas desenvolvidas segundo o Standard Methods for the Examination of Water and Wastewater (APHA/AWWA/ WEF, 1998).

A coleta do biogás produzido nos reatores UASB era realizada por uma válvula de três vias conectada ao sistema de saída do gás. Após o ponto de coleta, realizava-se a medida da vazão de gás por meio de um medidor wet gasmeter (Ritter, Tipo TG 05, Modelo 1-4, Capacidade 1 a $60 \mathrm{dm}^{3} / \mathrm{h}$ ). O biogás era analisado por cromatografia gasosa, para determinação do teor de metano e dióxido de carbono. As análises eram realizadas em um cromatógrafo Perkin-Elmer Autosystem XL GC, equipado com detector de condutividade térmica (TCD), utilizando coluna empacotada e hélio como gás de arraste. As temperaturas do forno e do detector eram de 60 e $150^{\circ} \mathrm{C}$, respectivamente, e o volume de gás injetado era de 0,5 mL. A frequência de análise do biogás era de duas vezes por semana.

A caracterização da biomassa foi realizada para diferentes pontos ao longo da altura do reator UASB (25 e $125 \mathrm{~cm}$, no sistema em escala piloto; 20 e 120 cm, no sistema em escala de demonstração), com determinação do teor de polímeros extracelulares, da distribuição granulométrica, da atividade metanogênica e da estabilidade do lodo. Determinou-se, ainda, o teor de sólidos totais e voláteis para as diferentes alturas do reator. Os coeficientes de produção de sólidos foram calculados determinando-se a massa de sólidos descartada dos reatores UASB e a massa de sólidos perdida com o efluente, e referenciados em relação à DQO aplicada e à DQO removida durante cada fase operacional. A descrição dos parâmetros de monitoramento é apresentada a seguir.

\section{Distribuição granulométrica}

A determinação da distribuição granulométrica foi realizada de acordo com metodologia descrita por Laguna et al (1999), tendo sido coletadas amostras de lodo nas diferentes alturas do reator e avaliadas as frações de sólidos retidas em peneiras de 2,38, 0,71 e 0,30 mm. Um volume de $25 \mathrm{~mL}$ de amostra de lodo era adicionado à sequência de peneiras $(2,38,0,71$ e 0,30 mm) e acrescentava-se água de torneira para lavagem da amostra até a completa remoção do excesso de material retido no peneiramento. Por meio da inversão das peneiras e de uma contralavagem, coletava-se o lodo retido. A determinação da porcentagem de grânulos retidos no peneiramento era realizada a partir do cálculo da massa retida em cada peneira e da massa total de sólidos no lodo determinada inicialmente. A determinação da distribuição granulométrica foi realizada semanalmente durante cada fase operacional.

\section{Polímeros extracelulares}

Dentre os métodos de extração de polímeros extracelulares apresentados na literatura, optou-se pelo uso do método de extração 
com vapor, descrito por Zhang, Bishop e Kinkle (1999), que apresentava maior rendimento para a extração de proteínas em relação aos outros métodos, sendo também adequado para a extração de lipídeos e carboidratos. Os procedimentos utilizados no método de extração com vapor consistiram inicialmente de uma lavagem do lodo, com adição de água deionizada em 2 g de lodo, seguido da agitação, centrifugação da amostra a 3500 rpm e separação da água de lavagem. Após a lavagem inicial, realizavam-se a adição de água deionizada ao lodo centrifugado e uma agitação por um minuto em um vortex. Em seguida, as duas frações obtidas (água de lavagem + lodo do vortex) eram misturadas, mantidas em um banho de vapor a $80{ }^{\circ} \mathrm{C}$, por dez minutos e, posteriormente, centrifugadas a 4000 rpm. Após a centrifugação, separava-se e filtrava-se o sobrenadante para análise do teor de carboidratos, proteínas e lipídeos. A determinação de polímeros extracelulares foi realizada semanalmente durante cada fase operacional.

\section{Atividade metanogênica específica e estabilidade do lodo}

A partir do teste de atividade metanogênica específica (AME), foi avaliada a capacidade do lodo em produzir metano a partir de acetato em condições otimizadas. O teste foi realizado de acordo com a metodologia descrita por Chernicharo (1997), com a utilização de um aparelho modelo Oxitop ${ }^{\circledR}$ Control AN-6, com cabeças de medição Oxitop ${ }^{\circledR} \mathrm{C}$ da WTW. Para a determinação da estabilidade do lodo, substituíram-se as soluções de acetato, tampão e nutrientes, apresentadas por Chernicharo (1997) para o teste de AME, por água, e utilizou-se o mesmo aparelho na realização do teste. A determinação da AME e da estabilidade do lodo foram realizadas mensalmente durante a pesquisa.

Para o cálculo da AME, foram construídas as curvas de produção de metano ao longo do período do teste e, a partir do trecho retilíneo das curvas médias de produção de metano, que coincide com uma taxa de produção aproximadamente constante, aplicou-se regressão linear, tendo sido obtidas as respectivas linhas de tendência, com suas equações e coeficientes de determinação. A inclinação da reta indicava a taxa de produção de metano $\left(\mathrm{mLCH}_{4} \cdot \mathrm{d}^{-1}\right)$ em cada um dos ensaios. A partir da taxa de produção de metano e da quantidade inicial de biomassa, obtinha-se a AME do lodo $\left(\mathrm{mLCH}_{4} \cdot \mathrm{d}^{-1} \cdot \mathrm{gSVT}^{-1}\right)$. O cálculo da estabilidade do lodo foi realizado a partir da determinação da massa inicial de sólidos voláteis utilizada no teste e da produção de metano, durante um período de um mês ou até a produção de gás atingir valores estáveis, próximos a zero.

Determinava-se a DQO convertida em metano (DQO- $\left.\mathrm{CH}_{4}\right)$, por meio da medida do volume do biogás produzido e da análise do seu teor de metano. Sabendo-se a DQO da massa inicial de sólidos voláteis $\left(\mathrm{DQO}_{\text {inicial }}\right)$ utilizada no teste, o cálculo da estabilidade era realizado determinando-se a porcentagem de $\mathrm{DQO}_{\text {inicial }}$ presente no lodo que ainda poderia ser estabilizada em ambiente anaeróbio e convertida em metano (DQO- $\mathrm{CH}_{4} / \mathrm{DQO}_{\text {inicial }} \times 100$ ).

\section{Resultados e discussão}

Os resultados obtidos com os dois sistemas de tratamento são apresentados e discutidos à luz dos possíveis efeitos do retorno do lodo aeróbio (produzido no FBP) sobre as características da biomassa no interior do reator UASB. Dessa forma, os resultados são sempre analisados comparativamente: entre as fases 1 e 2 para o sistema em escala piloto, e entre as fases 3 e 4 para o sistema em escala de demonstração. Para a maioria dos parâmetros monitorados, são inicialmente avaliadas as alterações que ocorreram na biomassa localizada na parte inferior do leito de lodo $(25 \mathrm{~cm}$ para o reator UASB em escala piloto e $20 \mathrm{~cm}$ para o reator UASB em escala de demonstração) e, posteriormente, na biomassa localizada na parte superior do leito de lodo (125 cm para o reator em escala piloto e $120 \mathrm{~cm}$ para o reator em escala de demonstração).

As Figuras 3 a 10 mostram os resultados médios dos parâmetros avaliados durante a pesquisa, comparativamente entre as fases sem e com retorno de lodo. Para se avaliar a existência de diferenças estatisticamente significativas entre os resultados médios, devido ao retorno de lodo, foi necessário verificar, inicialmente, o ajuste dos resultados à distribuição normal utilizando-se o método de Kolmogorov-Smirnov e, em seguida, comparando-se os valores médios das diferentes fases por meio do método $t$ de Student.

Adicionalmente, são apresentadas as principais condições operacionais a que os reatores UASB estiveram submetidos, assim como alguns indicadores comparativos de carga aplicada e de desempenho durante as fases sem e com retorno de lodo.

\section{Sólidos totais e voláteis}

Os resultados apresentados nas Figuras 3 e 4 indicam que ocorreram pequenas alterações nas concentrações médias de sólidos totais no lodo contido nos reatores UASB, notadamente para as amostras tomadas na parte inferior do reator em escala de demonstração e na parte superior de ambos os reatores. Enquanto uma redução de concentração foi observada para o lodo amostrado a $20 \mathrm{~cm}$ de altura no reator em escala de demonstração (de 5,4 para 4,6\%, da fase 3 para a fase 4), tendência contrária foi verificada para o lodo amostrado a 125 e 120 cm de altura, já que ocorreu um aumento da concentração do lodo nas fases em que se praticou o retorno de lodo, em ambos os reatores.

Avaliou-se, também, a porcentagem de sólidos voláteis em relação à concentração de sólidos totais ao longo das diferentes alturas no reator. A caracterização da biomassa no reator UASB em escala piloto indicou porcentagens médias de SVT de 62 e 64\%, para as fases 1 e 2 , respectivamente. Todavia, não foram encontradas diferenças estatísticas significativas entre os percentuais de SVT obtidos nessas duas fases. Tendência contrária foi observada no sistema em escala de demonstração, tendo ocorrido um decréscimo na porcentagem média de SVT, de $67 \%$ na fase 3, para $60 \%$ na fase 4 , indicativo 
de que o retorno de lodo não prejudicou o grau de estabilização do lodo no reator UASB.

\section{Produção de sólidos}

Na Tabela 4 são apresentados os coeficientes de produção específica média de sólidos totais, obtidos para os reatores UASB em escala piloto (fases 1 e 2) e em escala de demonstração (fases 3 e 4). Os coeficientes foram expressos em termos de massa de DQO removida $\left(\mathrm{Y}_{1}\right)$ e em termos de massa de DQO aplicada $\left(\mathrm{Y}_{2}\right)$, considerando os sólidos descartados dos reatores e também os sólidos perdidos com o efluente. A somatória dessas duas parcelas corresponde ao coeficiente global de produção específica de sólidos.

Os resultados obtidos durante as fases 1 e 2 foram próximos aos apresentados por Gonçalves (2001), que observaram uma produção específica de sólidos de 0,14 a 0,16 $\mathrm{kgST}_{\mathrm{kgDQO}}$ removida $^{-1}$ para um reator UASB utilizado para tratamento combinado de esgotos domésticos e lodo excedente de um biofiltro aerado submerso. Para o sistema em escala de demonstração, foram observados valores mais elevados para a produção específica de sólidos. Esses resultados se devem, provavelmente, à ausência de retentor de escuma no reator anaeróbio e, consequentemente, a uma maior perda de sólidos no efluente. Deve-se salientar que foram encontrados valores muito próximos para a produção específica de sólidos, durante as fases 3 e 4 da pesquisa. Esses resultados se justificam pela alimentação do sistema de tratamento com esgoto que apresentava alta concentração de sólidos (esgoto sanitário + lodo de adensadores) durante os 30 dias anteriores à fase 1 da pesquisa, ocasionando maiores valores para a produção de sólidos durante a fase 1 .

\section{Distribuição granulométrica}

Os resultados apresentados nas Figuras 5 e 6 indicam que houve alterações na distribuição granulométrica do lodo contido nos reatores UASB; todavia, só foram encontradas diferenças estatisticamente significativas para o lodo coletado a $25 \mathrm{~cm}$ de altura do reator UASB em escala piloto. Neste, ocorreu o aumento na porcentagem média de partículas com dimensões maiores que 2,38 mm (de 3,1 para 6,1\%) e com dimensões entre 0,71 e 2,38 mm (de 13,0 para 20,6\%); e a diminuição na porcentagem média de partículas menores que $0,71 \mathrm{~mm}$ (de 83,4 para 73,3\%). A análise conjunta dos resultados obtidos para os dois sistemas indica que o retorno de lodo não ocasionou a diminuição do tamanho médio das partículas de lodo na parte inferior do reator UASB.

Nos pontos mais elevados do reator, ocorreu um efeito contrário ao observado a 20 e $25 \mathrm{~cm}$ de altura, com diminuição no tamanho das partículas das fases sem retorno de lodo para as fases com retorno de lodo, tanto para o sistema em escala piloto quanto para o sistema em escala de demonstração. Essas alterações no tamanho das partículas podem estar associadas às modificações

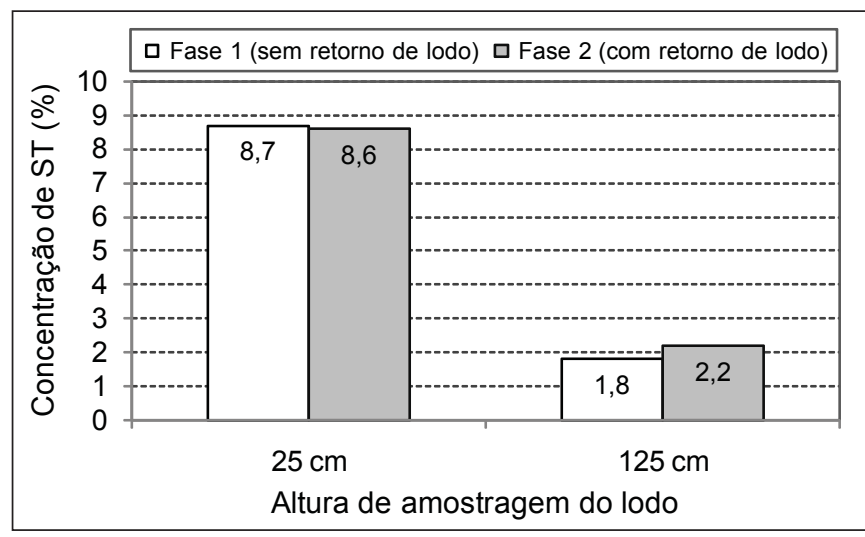

Figura 3 - Concentrações de sólidos totais em diferentes alturas e fases operacionais do reator UASB em escala piloto

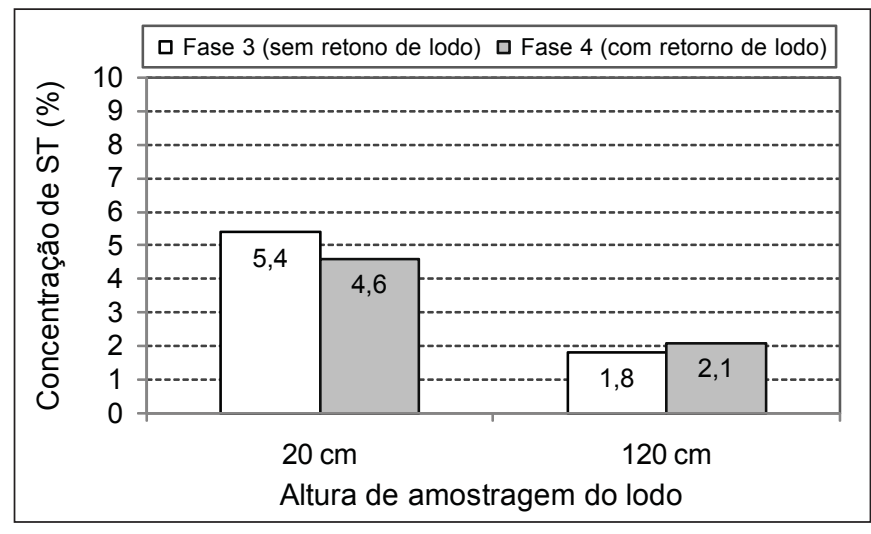

Figura 4 - Concentrações de sólidos totais em diferentes alturas e fases operacionais do reator UASB em escala de demonstração

Tabela 4 - Coeficientes de produção específica média de sólidos no reator UASB

\begin{tabular}{|c|c|c|c|c|c|c|}
\hline \multirow[b]{2}{*}{ Fase } & \multicolumn{3}{|c|}{$Y_{1}\left(g S T . g D Q O_{\text {removida }}{ }^{-1}\right)$} & \multicolumn{3}{|c|}{$Y_{2}\left(g S T . g D Q O_{\text {aplicada }^{-1}}{ }^{-1}\right.$} \\
\hline & $\begin{array}{c}\text { Sólidos descartados } \\
\text { do reator }\end{array}$ & $\begin{array}{l}\text { Sólidos perdidos } \\
\text { com o efluente }\end{array}$ & Global & $\begin{array}{c}\text { Sólidos descartados } \\
\text { do reator }\end{array}$ & $\begin{array}{l}\text { Sólidos perdidos } \\
\text { com o efluente }\end{array}$ & Global \\
\hline 1 & 0,09 & 0,08 & 0,17 & 0,06 & 0,05 & 0,11 \\
\hline 2 & 0,14 & 0,07 & 0,21 & 0,11 & 0,05 & 0,16 \\
\hline 3 & 0,14 & 0,13 & 0,27 & 0,11 & 0,10 & 0,21 \\
\hline 4 & 0,15 & 0,12 & 0,27 & 0,13 & 0,10 & 0,23 \\
\hline
\end{tabular}

Fonte: Pontes (2003). 


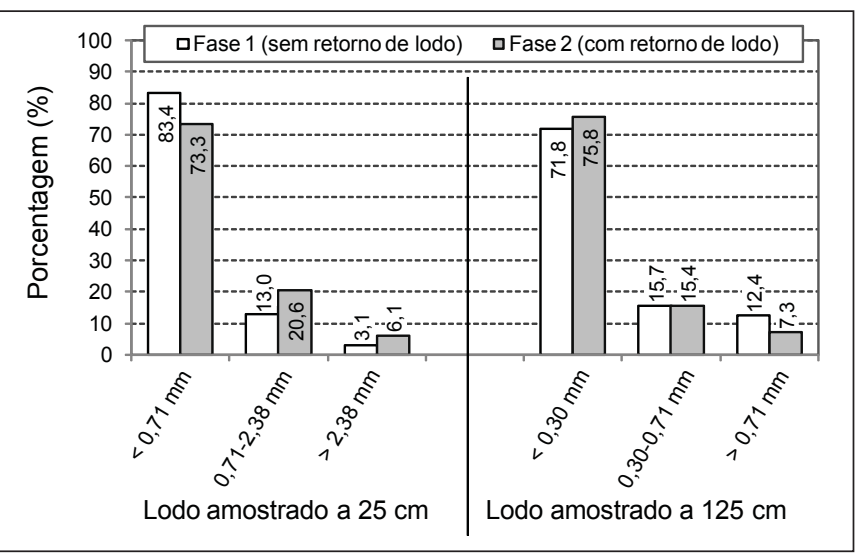

Figura 5 - Distribuição granulométrica do lodo coletado a 25 e a $125 \mathrm{~cm}$ de altura do reator UASB em escala piloto

nas características do despejo, pois os mecanismos de formação de grânulos estão relacionados, dentre outros fatores, às características do substrato (concentração e composição), que se modificou nas diferentes fases operacionais em função do retorno do lodo. A granulação do lodo, verificada no reator em escala piloto pode, ainda, ter sido influenciada pela presença e composição de polímeros extracelulares (carboidratos e proteínas), que podem interferir na agregação e na estabilidade do lodo anaeróbio (EL-MAMOUNI; LEDUC; GUIOT, 1999).

Outro fator que poderia ter afetado o tamanho das partículas seria o bombeamento semicontínuo do lodo, realizado durante as fases 2 e 4 . Com o acréscimo de vazão devido ao retorno de lodo, a velocidade ascensional no reator era alterada a cada 15 minutos, apresentando uma oscilação entre 1,0 e 1,4 m.h.' $\mathrm{h}^{-1}$, no sistema em escala piloto, e entre 0,5 e 0,6 m.h.-1, no sistema em escala de demonstração. Esse tipo de bombeamento pode ter provocado um efeito de pulsação no reator, que, de acordo com Franco, Roca e Lema (2002), poderia ocasionar a presença de um lodo com uma maior porcentagem de partículas finas, como ocorreu nos pontos mais elevados do reator. Foi possível observar, ainda, a presença de partículas de lodo com maiores dimensões nos pontos mais baixos do reator do sistema em escala piloto, que deve ter ocorrido devido às oscilações de velocidade durante a fase com retorno de lodo. Tais variações de velocidade podem ter proporcionado uma maior pressão seletiva sobre os micro-organismos, possivelmente favorecendo os mecanismos de agregação e granulação da biomassa mais adaptada às condições hidráulicas impostas.

\section{Polímeros extracelulares}

Os resultados apresentados nas Figuras 7 e 8 indicam que ocorreram alterações nas concentrações de carboidratos, proteínas e lipídeos no lodo contido nos reatores UASB. Para o lodo coletado a

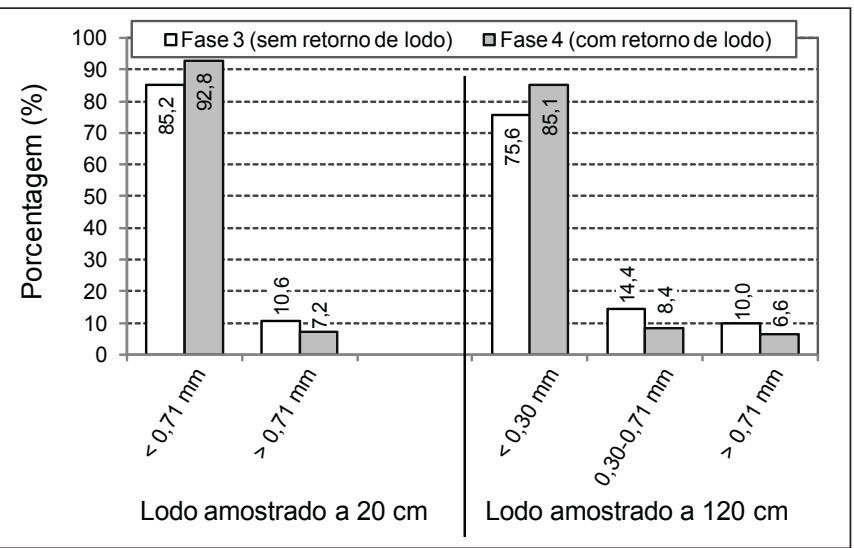

Figura 6 - Distribuição granulométrica do lodo coletado a 20 e a $120 \mathrm{~cm}$ de altura do reator UASB em escala de demonstração

$25 \mathrm{~cm}$ de altura no reator UASB em escala piloto, não foram observadas diferenças estatisticamente significativas entre os teores de polímeros extracelulares medidos para as fases 1 e 2. Entretanto, para o sistema em escala de demonstração, foi observado um aumento estatisticamente significativo para a concentração de proteínas extracelulares (de 41,5 para 66,0 mg.gSVT-1) e uma diminuição para lipídeos extracelulares (de 2,6 para 1,2 $\mathrm{mg} \mathrm{gSVT}^{-1}$ ), da fase 3 para a fase 4 .

$\mathrm{Na}$ presente pesquisa, observou-se um decréscimo na carga afluente de lipídeos do reator durante a fase 4 , bem como uma diminuição na adsorção de gordura no lodo coletado no ponto de amostragem 1, durante essa fase. De acordo com Vidal (2000), a adsorção de gordura no lodo pode limitar o transporte de substratos solúveis até a biomassa e causar um decréscimo na taxa de conversão de substratos. A menor concentração afluente de lipídeos pode, portanto, ter provocado uma diminuição na sua adsorção no lodo e um aumento na conversão de substratos, durante a fase 4 , no sistema em escala de demonstração. Para o sistema em escala piloto também foi observada essa menor carga afluente de lipídeos durante a fase com retorno de lodo (fase 2). Entretanto a menor adsorção de lipídeos não foi considerada estatisticamente significativa em relação à fase sem retorno de lodo (fase 1).

Os resultados obtidos para o lodo coletado a $125 \mathrm{~cm}$ de altura, no reator em escala piloto, indicaram um aumento estatisticamente significativo para as concentrações de carboidratos (de 19,9 para 29,1 mg.gSVT-1) e proteínas (de 62,4 para 93,2 mg.gSVT ${ }^{-1}$ ), da fase 1 para a fase 2. Para o sistema em escala de demonstração, não foram observadas diferenças significativas nas concentrações de polímeros extracelulares entre as duas fases. O aumento no teor de polímeros extracelulares no sistema em escala piloto pode ter sido outro fator que favoreceu a presença de partículas mais finas nesse ponto de amostragem da fase 2, quando o sistema operou com retorno de lodo. 


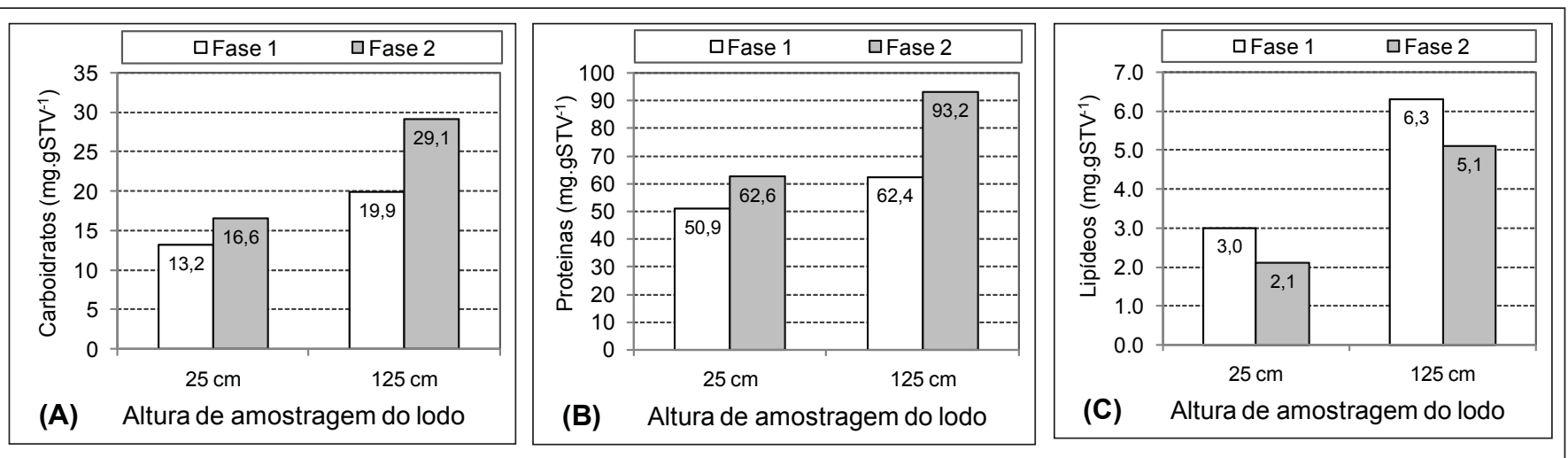

Figura 7 - Concentrações de carboidratos (A), proteínas (B) e lipídeos (C) em diferentes alturas e fases operacionais do reator UASB em escala piloto

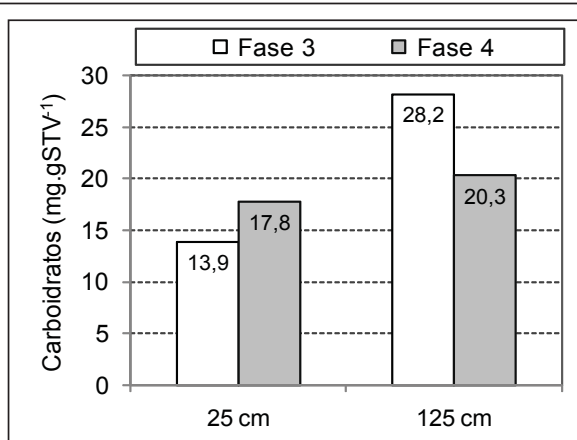

(A) Altura de amostragem do lodo

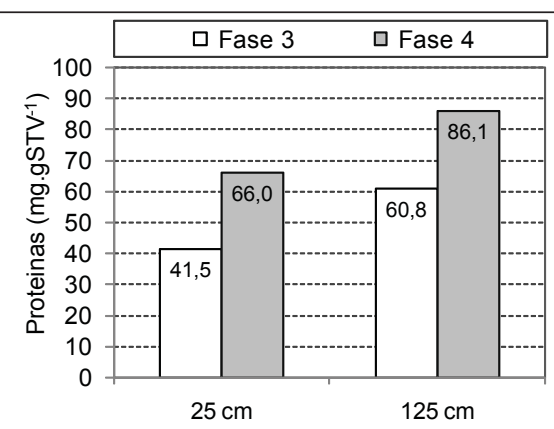

(B) Altura de amostragem do lodo

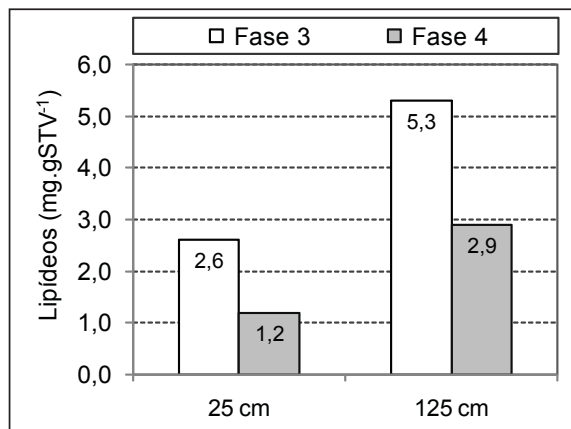

(C) Altura de amostragem do lodo

Figura 8 - Concentrações de carboidratos (A), proteínas (B) e lipídeos (C) em diferentes alturas e fases operacionais do reator UASB em escala de demonstração

\section{Estabilidade e atividade metanogênica específica do lodo}

Os resultados obtidos para a estabilidade e a atividade metanogênica específica do lodo são apresentados nas Figuras 9 e 10, respectivamente. Para o lodo do reator UASB em escala piloto, os resultados obtidos para os testes de estabilidade do lodo indicaram uma biodegradabilidade residual média em torno de $27 \%$ para as fases com e sem retorno de lodo. Esses resultados indicam que o retorno de lodo não prejudicou a estabilidade do lodo no reator UASB e que cerca de 27\% dos sólidos orgânicos presentes ainda eram biodegradáveis no ambiente anaeróbio, em ambas as fases.

Para o lodo do reator UASB em escala de demonstração, observou-se uma biodegradabilidade residual média de 27 e 32\% para as fases sem e com retorno de lodo, respectivamente. Esses valores foram próximos aos observados para o sistema em escala piloto, mas são superiores aos valores obtidos por Van Haandel e Lettinga (1994), que reportaram valores de $7 \%$ para o lodo de reator operado, com TDH $=5,6 \mathrm{~h}$, e de $19 \%$ para o reator operado com $\mathrm{TDH}=2,6 \mathrm{~h}$.

As AME médias do lodo do reator UASB em escala piloto foram de 0,4 e 0,5 gDQO-CH gSVT $^{-1} \cdot \mathrm{d}^{-1}$, para as fases sem e com retorno de lodo, respectivamente. Os resultados obtidos indicam que não houve impacto negativo do lodo aeróbio sobre a atividade do lodo no reator UASB, como havia sido observado por Jenícek, Dohányos e Zábranská (1999) para o retorno de lodo aeróbio para um reator anaeróbio compartimentado de fluxo ascendente. Isto se deve, provavelmente, a alta taxa de diluição do lodo aeróbio ao ser incorporado ao esgoto afluente no reator UASB $\left(0,5 \mathrm{~L} \cdot \mathrm{h}^{-1}\right.$ de lodo aeróbio para $74 \mathrm{~L} \cdot \mathrm{h}^{-1}$ de esgoto doméstico). Pode-se observar, ainda, que ocorreu uma aparente melhoria da atividade do lodo durante a fase em que se praticou o retorno de lodo, embora essa melhoria não tenha sido estatisticamente significativa. Ortega, Robles e Bohórquez (1996) observaram a mesma tendência de melhoria da atividade do lodo durante a fase com retorno de lodo aeróbio para o reator anaeróbio em seus experimentos, tendo ocorrido um aumento na AME, de 0,27 para 0,40 gDQO- $\mathrm{CH}_{4} \cdot \mathrm{gSVT}^{-1}$. $\mathrm{dia}^{-1}$. 


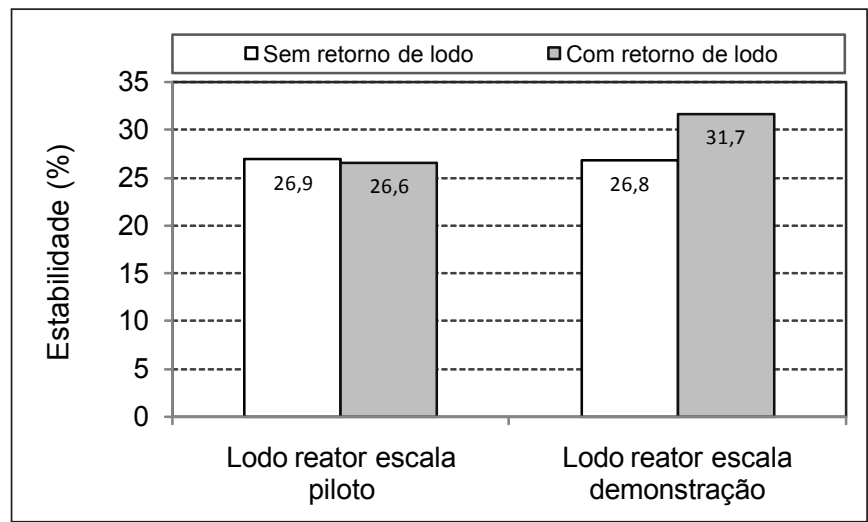

Figura 9 - Estabilidade do lodo nas diferentes fases operacionais dos reatores UASB em escala piloto e demonstração

Para o sistema em escala de demonstração, foram obtidos baixos valores de AME para o lodo coletado no reator UASB, da ordem de $0,1 \mathrm{gDQO}-\mathrm{CH}_{4} \cdot \mathrm{gSVT}^{-1} \cdot \mathrm{d}^{-1}$ para as fases 3 e 4 . Não foi observada uma modificação no valor da atividade metanogênica devido ao retorno de lodo.

\section{Acréscimo de carga hidráulica e carga orgânica}

Embora o lodo de retorno aeróbio apresente elevadas concentrações de DQO, DBO e SST, o impacto em termos de cargas aplicadas aos reatores UASB é mínimo, em decorrência dos pequenos volumes produzidos e das reduzidas vazões em que o retorno de lodo é praticado. Na presente pesquisa, as concentrações do esgoto bruto foram ligeiramente inferiores durante as fases em que se praticou o retorno de lodo, fazendo com que as cargas orgânicas volumétricas aplicadas aos reatores UASB fossem muito semelhantes durante as fases com e sem retorno de lodo, conforme apresentado na Tabela 3.

A título de exemplo, apresenta-se a seguir a estimativa do impacto do retorno do lodo sobre a carga hidráulica e carga orgânica afluente ao reator UASB. Os cálculos foram feitos considerando-se a vazão média de alimentação do sistema em escala de demonstração e dados de entrada considerados típicos para a fase líquida e fase sólida, conforme Tabela 5 e Equações 1 a 5 . Como se pode verificar, o acréscimo de carga hidráulica é inferior a $1 \%$, enquanto o acréscimo de carga orgânica é de 5\%. Ambos os acréscimos de carga são perfeitamente assimiláveis pelo reator UASB.

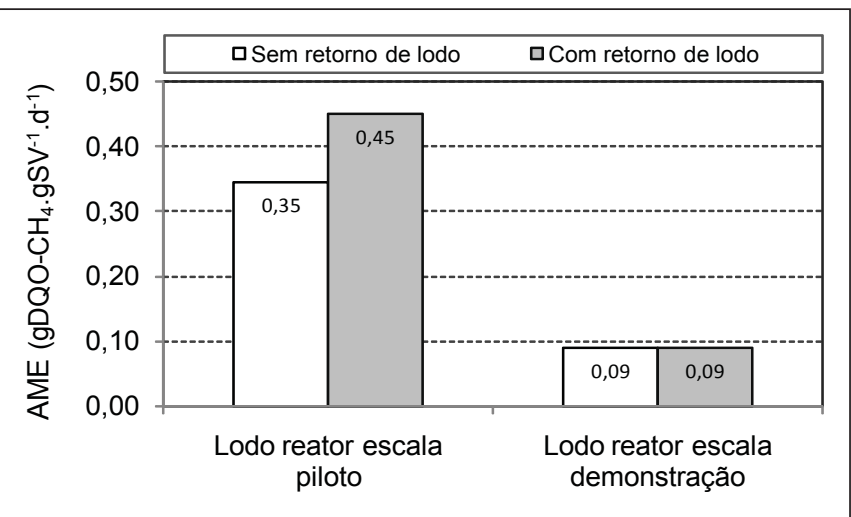

Figura 10 - AME do lodo nas diferentes fases operacionais dos reatores UASB em escala piloto e demonstração

- Volume de lodo produzido diariamente no FBP $\left(\mathrm{V}_{\text {lodo }}\right)$ : $V_{\text {lodo }}=\frac{Y X Q_{a} X\left(S_{\text {UASB }}-S_{\text {FEP }}\right)}{Y X C_{\text {lodo }}}=\frac{0,75 \times 69 \times(0,100-0,030)}{1.020 \times 0,01}=0,355 \mathrm{~m}^{3} \cdot d^{-1}$ Equação 1

- Carga orgânica no lodo do FBP retornado para o reator UASB $\left(\mathrm{CO}_{\text {lodo }}\right)$ :

$\mathrm{CO}_{\text {lodo }}=\mathrm{V}_{\text {lodo }} \mathrm{XS}_{\text {lodo }}=0,355 \times 3,0=1,07 \mathrm{kgDBO} \cdot \mathrm{d}^{-1}$

Equação 2

- Carga orgânica no esgoto bruto afluente ao reator UASB (sem o lodo de retorno):

$\mathrm{CO}_{\text {esgoto bruto }}=\mathrm{Q}_{\mathrm{a}} \times \mathrm{S}_{0}=69 \times 0,300=20,7 \mathrm{kgDBO} \cdot \mathrm{d}^{-1} \quad$ Equação 3

- Percentual de acréscimo de carga hidráulica decorrente do retorno de lodo:

$\mathrm{V}_{\text {lodo }}=0,355=0,5 \%$

$\begin{array}{lll}\mathrm{Q}_{\mathrm{a}} & 69 & \text { Equação } 4\end{array}$

- Percentual de acréscimo de carga orgânica decorrente do retorno de lodo:

$\frac{\mathrm{CO}_{\text {espodoto bruto }}}{\mathrm{Co}_{\text {of }}}=\frac{1,07}{20,7}=5 \%$

Equação 5

\section{Desempenho dos sistemas de tratamento}

As concentrações médias de DQO, DBO e SST do esgoto afluente e dos efluentes dos reatores UASB e dos FBPs em escala piloto e

Tabela 5 - Dados considerados na estimativa do acréscimo de carga hidráulica e carga orgânica decorrente do retorno de lodo aeróbio para o reator UASB

\begin{tabular}{|c|c|c|c|c|c|c|c|}
\hline \multicolumn{4}{|c|}{ Dados da fase líquida } & \multicolumn{4}{|c|}{ Dados da fase sólida (lodo aeróbio do FBP) } \\
\hline $\begin{array}{l}Q_{a} \\
\left(m^{3} \cdot d^{-1}\right)\end{array}$ & $\begin{array}{c}\mathrm{S}_{0} \\
\left(\mathrm{kgDBO} \cdot \mathrm{m}^{-3}\right)\end{array}$ & $\begin{array}{c}\mathrm{S}_{\mathrm{UASB}} \\
\left(\mathrm{kgDBO} \cdot \mathrm{m}^{-3}\right)\end{array}$ & $\begin{array}{c}\mathrm{S}_{\mathrm{FBP}} \\
\left(\mathrm{kgDBO} \cdot \mathrm{m}^{-3}\right)\end{array}$ & 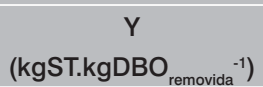 & $\begin{array}{c}\gamma \\
\left(\mathrm{kg} \cdot \mathrm{m}^{-3}\right)\end{array}$ & $\begin{array}{l}\mathrm{C}_{\text {lodo }} \\
(\%)\end{array}$ & $\begin{array}{c}\mathrm{S}_{\text {lodo }} \\
\left(\mathrm{kgDBO} \cdot \mathrm{m}^{-3}\right)\end{array}$ \\
\hline 69 & 0,300 & 0,100 & 0,030 & 0,75 & 1.020 & 1,0 & 3,0 \\
\hline
\end{tabular}

$\mathrm{Q}_{\mathrm{a}}$ : vazão de esgoto afluente ao sistema de tratamento; $\mathrm{S}_{0}$ : concentração de DBO do esgoto bruto; $\mathrm{S}_{\mathrm{UASB}}$ : concentração de DBO do efluente do reator UASB; $\mathrm{S}_{\mathrm{FBP}}$ : concentração de DBO do efluente do FBP; Y: coeficiente de produção de lodo aeróbio no FBP; $\gamma$ : massa específica do lodo aeróbio; $\mathrm{C}_{\text {lodo }}$ : concentração de sólidos no lodo aeróbio retirado do decantador do FBP. $\mathrm{S}_{\text {lodo }}$ : concentração de DBO do lodo aeróbio produzido no FBP. 


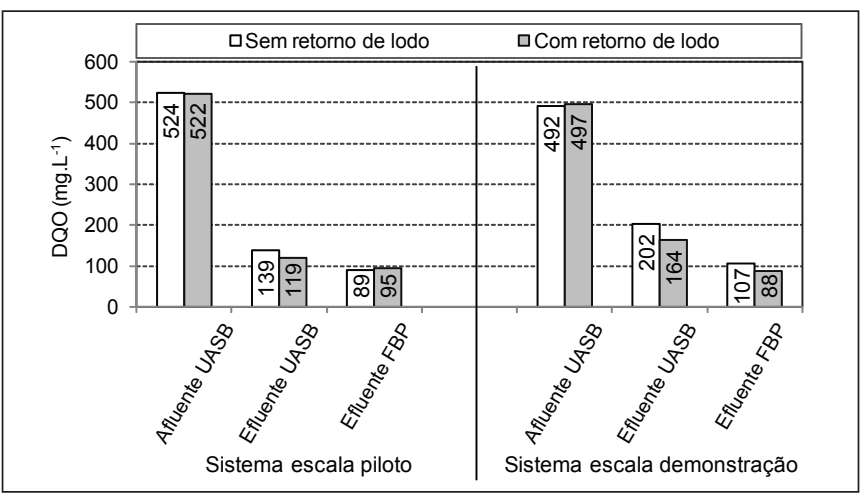

Figura 11 - Concentrações de DQO nas diferentes fases operacionais dos sistemas em escala piloto e demonstração

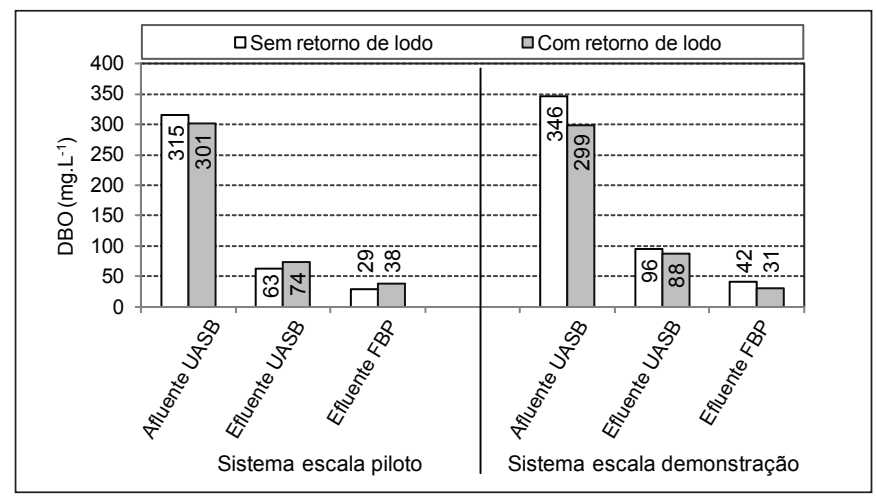

Figura 13 - Concentrações de DBO nas diferentes fases operacionais dos sistemas em escala piloto e demonstração

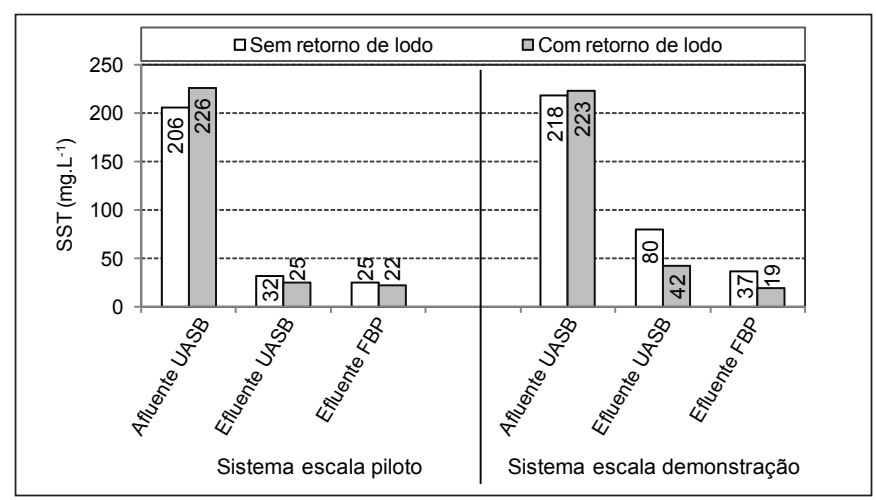

Figura 15 - Concentrações de SST nas diferentes fases operacionais dos sistemas em escala piloto e demonstração

demonstração para as diferentes condições operacionais da pesquisa são apresentadas nas Figuras 11, 13 e 15, enquanto as Figuras 12 e 14 mostram as respectivas eficiências médias de remoção de DQO e DBO.

Como se pode observar, o retorno do lodo aeróbio não afetou negativamente o desempenho do reator UASB e do FBP. Ao contrário, boa parte dos resultados indica menores concentrações efluentes durante as fases em que se praticou o retorno do lodo tanto para os reatores UASB quanto para os FBPs. Muito embora as diferenças

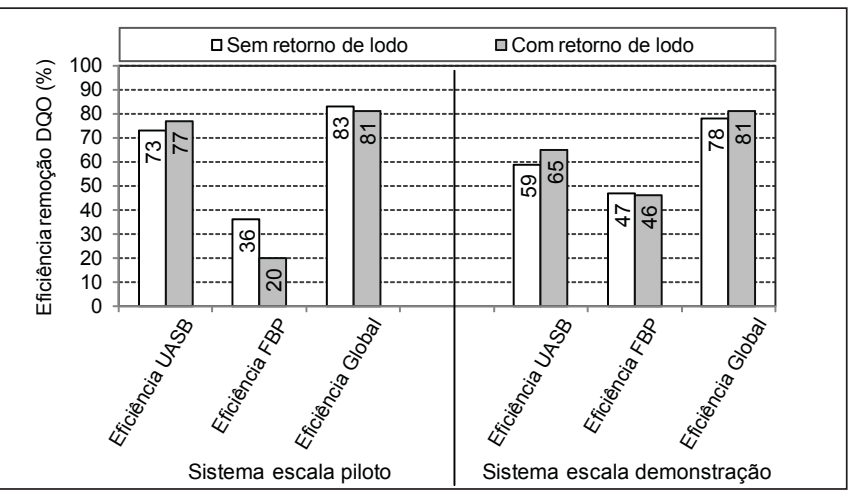

Figura 12 - Eficiências de remoção de DQO nas diferentes fases operacionais dos sistemas em escala piloto e demonstração

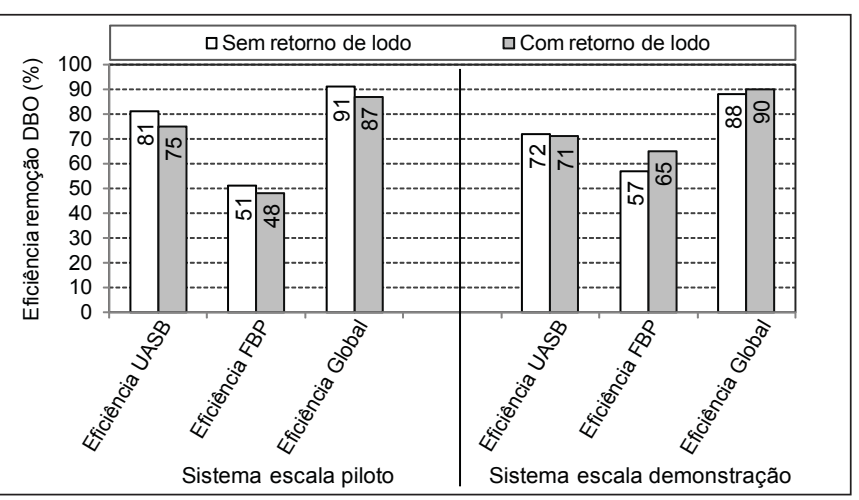

Figura 14 - Eficiências de remoção de DBO nas diferentes fases operacionais dos sistemas em escala piloto e demonstração

de concentrações e eficiências entre as fases com e sem retorno de lodo não tenham sido confirmadas estatisticamente.

\section{Conclusões}

Os resultados da pesquisa indicaram que a prática de retorno do lodo aeróbio produzido em FBPs, para adensamento e digestão em reatores UASB tratando esgotos domésticos, ocasionou algumas alterações nas características da biomassa presente nos reatores UASB. No entanto, só foram encontradas diferenças estatisticamente significativas para a distribuição granulométrica do lodo e para o teor de polímeros extracelulares. Observou-se uma diminuição no tamanho das partículas de lodo nos pontos mais elevados dos reatores anaeróbios e um aumento no tamanho das partículas de lodo a $25 \mathrm{~cm}$ de altura no sistema em escala piloto e, ainda, uma diminuição no teor de lipídeos extracelulares e um aumento no teor de proteínas extracelulares a $20 \mathrm{~cm}$ de altura no sistema em escala de demonstração, bem como um aumento no teor de proteínas e carboidratos extracelulares a $125 \mathrm{~cm}$ de altura no sistema em escala piloto.

O aumento na porcentagem média de partículas finas nos pontos mais elevados do reator UASB, durante as fases com retorno de lodo (sistema em escala piloto e em escala de demonstração), pode estar associado às modificações nas características do despejo, à presença 
e composição de polímeros extracelulares (carboidratos e proteínas) e ao bombeamento semicontínuo do lodo de retorno. Esse aumento na porcentagem de partículas finas e a maior produção específica de sólidos durante as fases com retorno de lodo tornaram necessária a realização de descartes mais frequentes de lodo no reator UASB para evitar a perda de sólidos no efluente do reator.

Apesar das alterações de algumas características da biomassa, não foi observado qualquer efeito negativo sobre o desempenho dos reatores UASB e dos sistemas de tratamento como um todo. As concentrações efluentes de DQO foram sempre muito próximas, da ordem de 120 a $140 \mathrm{mg} \cdot \mathrm{L}^{-1}$ para o reator UASB em escala piloto, e 160 a 200 mg. $L^{-1}$ para o reator UASB em escala de demonstração. É interessante ressaltar que os valores inferiores dessas faixas foram obtidos para os sistemas operando com retorno de lodo. Em relação ao parâmetro $\mathrm{DBO}$, as concentrações efluentes também estiveram muito próximas, entre 65 e $75 \mathrm{mg} . \mathrm{L}^{-1}$ para o reator em escala piloto, e 90 a $95 \mathrm{mg} \cdot \mathrm{L}^{-1}$ para o reator em escala de demonstração. Concentrações efluentes de SST muito baixas foram observadas para o reator em escala piloto, entre 25 e $30 \mathrm{mg} \cdot \mathrm{L}^{-1}$, enquanto para o reator em escala de demonstração foram relativamente mais elevadas, de 40 a 80 mg. $\mathrm{L}^{-1}$, mas ainda compatíveis com o que se observa em reatores em escala plena.

As porcentagens médias de SVT nos lodos dos reatores UASB operando com retorno de lodo foram de 64 e $60 \%$, para os sistemas em escala piloto e em escala de demonstração, respectivamente, indicando que o retorno de lodo não provocou um aumento na concentração de sólidos voláteis nos reatores. Ocorreu, entretanto, um aumento na produção específica de sólidos no sistema em escala piloto, durante a fase com retorno de lodo, tendo-se obtido valores de 0,17 $\mathrm{gST} . g D Q O_{\text {removida }^{-1}}$ e 0,21 $\mathrm{gST} . \mathrm{gDQO}_{\text {removida }}{ }^{-1}$ para as fases sem e com retorno de lodo, respectivamente. Para o sistema em escala de demonstração, foram obtidos valores muito próximos para a produção de sólidos durante as fases sem e com retorno de lodo, da ordem de 0,27 gST.gDQO removida $^{-1}$.

Para o sistema em escala piloto, a biodegradabilidade residual média do lodo anaeróbio foi de $27 \%$ durante as duas fases operacionais, enquanto a atividade metanogênica específica média foi de 0,4 e 0,5 gDQO-CH gSVT $^{-1} \cdot \mathrm{d}^{-1}$ para as fases sem e com retorno de lodo, respectivamente. Para o sistema em escala de demonstração, os valores obtidos para a biodegradabilidade residual média foram de 27 e $32 \%$ nas fases sem e com retorno de lodo, respectivamente. A atividade metanogênica específica média foi de 0,1 DQO- $\mathrm{CH}_{4} \cdot \mathrm{gSVT}^{-1} \cdot \mathrm{d}^{-1}$, durante as duas fases operacionais.

\section{Agradecimentos}

Os autores agradecem ao Conselho Nacional de Desenvolvimento Científico e Tecnológico (CNPq) pelas bolsas concedidas, à Fundação de Amparo à Pesquisa do Estado de Minas Gerais (Fapemig) e à Financiadora de Estudos e Projetos (Finep), por meio do Programa de Pesquisa em Saneamento Básico (Prosab), pelo financiamento da pesquisa.

\section{Referências}

AWWA/APHA/WEF. Standard methods for examination of water and wastewater. 20. ed. Washington: APHA, 1998.

CHERNICHARO, C.A.L. Princípios do tratamento anaeróbio de águas residuárias: volume 5 - reatores anaeróbios. Belo Horizonte: Desa/ UFMG, 1997

CUERVO-LOPEZ, F.M. et al Effect of nitrogen loading rate and carbon source on denitrification and sludge settleability in upflow anaerobic sludge blanket reactors, Water Science and Technology, v. 40, n. 8, p. 123-130, 1999

EL-MAMOUNI, R.; LEDUC, R.; GUIOT, S.R. Influence of synthetic and natural polymers on the granulation process. Water Science and Technology, v. 38, n. 8-9, p. 341-347, 1998.

FRANCO, A.; ROCA, E.; LEMA, J.M. Improvement of the properties of granular sludge in UASB reactors, by flow pulsation. In: VII LATINAMERICAN WORKSHOP AND SEMINAR ON ANAEROBIC DIGESTION,
Proceedings... Mérida: Associação Interamericana de Engenharia Sanitária e Ambiental, p. 228-235, 2002.

GONÇALVES, R.F. et al. Desempenho de um reator UASB na digestão de esgoto sanitário e lodo aeróbio descartado de biofiltros aerados submersos - Escala 1000 habitantes. In: XXI CONGRESSO BRASILEIRO DE ENGENHARIA SANITÁRIA E AMBIENTAL, Anais... João Pessoa: Associação Brasileira de Engenharia Sanitária e Ambiental - ABES, 2001.

JENÍCEK, P.J.; DOHÁNYOS, M.; ZÁBRANSKÁ, J. Combined anaerobic treatment of wastewater and sludge. Water Science and Technology, v. 40, n. 1, p. 85-91, 1999.

LAGUNA, A. et al. A simple and low cost technique for determining the granulometry of upflow anaerobic sludge blanket reactor sludge. Water Science and Technology, v. 40, n. 8, p. 1-8, 1999.

ORTEGA, C.L.; ROBLES, A.N.; BOHÓRQUEZ, S.S. Efecto de lodos ativados de purga sobre el funcionamento de un reator UASB piloto $y$ 
las caracteristicas del lecho de lodo granular. In: XXV CONGRESSO PANAMERICANO DE INGIENIERIA SANITARIA E AMBIENTAL, Anais... Mexico: Aidis, 1996

PONTES, P.P. Reatores UASB aplicados ao tratamento combinado de esgotos sanitários e lodo excedente de filtro biológico percolador. 220f. Tese (Doutorado em Saneamento, Meio Ambiente e Recursos Hídricos) - Escola de Engenharia da UFMG, Belo Horizonte, 2003.
VAN HAANDEL, A.C.; LETTINGA, G. Tratamento anaeróbio de esgotos: um manual para países de clima quente. Campina Grande: EPGRAF, 1994

VIDAL, G. et al. Influence of the content of fats and proteins on the anaerobic biodegradability of dairy wastewater. Bioresource Technology, v. 74, p. 231-239, 2000.

ZHANG, X.; BISHOP, P.L.; KINKLE, B.K. Comparison of extraction methods for quantifying extracellular polymers in biofilms. Water Science and Technology, v. 39, n. 7, p. 211-218, 1999. 